\title{
10. Subjective Wellbeing and the Mismeasure of Progress
}

\author{
Richard Eckersley
}

\section{Introduction}

The past two decades have seen a remarkable surge in interest in measuring the progress of societies. The debate has focused on adequacy of economic indicators, notably per capita income or GDP (gross domestic product). Measures of subjective wellbeing (SWB) are attracting particular attention, with several national statistical agencies, including the Australian Bureau of Statistics (ABS), examining their value for inclusion in sets of indicators of national progress.

The statistical models of progress have a high degree of internal consistency: all or most of the dominant indicators are correlated. Some economists say GDP is associated with so many other measures of progress (including SWB) that we might as well continue to use GDP. Some SWB researchers, on the other hand, say SWB is associated with so many other, objective measures of progress, we should use SWB. Most researchers, however, opt for a mix of subjective and objective indicators.

So what is the problem? My argument is that conventional indicators of progress, including GDP and SWB, are measuring Westernisation or modernisation, rather than optimal social progress or development. While the concepts may overlap, they are not the same thing. At best, the qualities being measured may be desirable, even necessary, but are not sufficient. At worst, the benefits of modernisation are being counted, but not its costs, including those associated with excessive materialism and individualism (to say nothing of its environmental impacts, with which I am not concerned here).

In other words, indicators focus on those qualities that modernisation emphasises and celebrates, such as material wealth, education, democratic governance, the rule of law, human rights and individual freedom. Valuable though these qualities are, they do not represent the sum total of what makes a better life.

The goal of progress should be to improve people's quality of life, not just to raise their standard of living. Quality of life is the degree to which people enjoy - or societies provide - the conditions of life (social, economic, cultural, environmental) that are conducive to total wellbeing (physical, mental, social and spiritual). Quality of life is both subjective and objective, as much a matter 
of how we feel about our lives as about the material conditions in which we live. Subjective wellbeing has been defined in many ways, but is usually measured on a scale of self-reported happiness or life satisfaction.

I set out in more detail the case against orthodox models and measures of progress in several recent papers (Eckersley: 2006a, 2009, 2012, in press). The orthodox view places Western liberal democracies at its leading edge; other evidence suggests they may be, in some respects at least, societies in decline. Reconciling these views is no simple matter.

In this chapter I want to take two aspects of SWB that are raised by a new paper by Ed Diener and his colleagues, which is one of the most persuasive and compelling accounts in favour of SWB measures (Diener, Inglehart, Tay: in press). The first is the gap - or contradiction - between personal life satisfaction and social discontent; the second concerns the role of personal freedom in SWB.

All these matters would have been of keen interest to Ian Castles. They reflect both the continuities in the debate about progress and its developments and advances since his time. In his response to the papers presented at the 1997 conference, 'Measuring national progress: Is life in Australia getting better, or worse?', Ian said that he had listened to the presentations with a sense of déjà vu (Castles: 1998). I suspect he would say the same about these symposium papers. Ian concluded by saying that while GDP was sometimes misused, the view that decision-makers were misled is rarely supported by evidence. 'In my view, GDP is a valuable and necessary, but not sufficient, measure of material progress.'

Ian even drew on SWB measures to support his case at an ASSA workshop later that same year (Castles: 1997). In his presentation, a critique of the Human Development Index and the Genuine Progress Indicator, he stated that the objective indicator of wellbeing which correlated best with the subjective measure of wellbeing was GDP per head:

It would be unwise to draw strong inferences from these findings, but it is interesting that an indicator which was never intended to be a measure even of economic welfare should appear to be better correlated with the subjective wellbeing measure than several indicators which embrace non-economic aspects of wellbeing, and also of a composite indicator which was designed to embrace economic and non-economic aspects.

Ian and I were often on opposite sides of the debate about progress, although I had great respect for his statistical knowledge and rigour; our differences were more philosophical. I do think, for example, that governments have been misled 
- or mistaken - in persisting with a model of material progress, focused on growth in GDP, in the face of growing evidence of its declining benefits and rising costs, including to wellbeing (Eckersley: 2005, 2006a, b).

\section{Personal satisfaction and social disquiet}

The new paper by Diener and colleagues carefully reviews the reliability, validity and sensitivity of life satisfaction measures. They argue that several types of data indicate that the measures validly reflect the quality of people's lives. These lines of evidence include: differences between nations in life satisfaction, which are associated with differences in objective conditions; differences between groups who live in different circumstances; patterns of change in life satisfaction before, during, and after significant life events; and prediction by life satisfaction scores of future behaviours such as suicide.

Despite this, they remain cautious about using SWB indicators to inform national policy decisions. The measures are useful in research on individual wellbeing, but there are questions about applying them to policy that need more analysis and research, they say.

Life satisfaction can provide an added window on what is going well or badly in a society, as experienced by the citizens themselves. There are specific instances where life satisfaction measures can help illuminate current policy debates, but being able to tie the scores to factors that bear on policy is essential. Given their low cost and ease of administration it is desirable that societies adopt measures of life satisfaction to supplement current economic and social indicators. At the same time it must be recognised that life satisfaction measures have clear limits, and provide only one type of information to policy makers. Thus, additional types of objective and subjective indicators are needed.

The authors report research findings that help to explain something that I have pointed out repeatedly in my writing: asking people about life in general or the lives of others gives a very different result from asking them about their own lives (Eckersley: 2000a,b, 2005, 2009, 2012, in press).

In the study in question, political questions sometimes came before, and sometimes after, the life evaluation question. People's life evaluation scores were lower when they followed the political questions (a draft stated that the scores were 'substantially lower' and that this item-order effect was 'relatively large'). Inserting a buffer or transition question - 'Now, thinking about your personal life, are you satisfied with your personal life today?' - between the political questions and life evaluation largely eliminated this item-order effect. The authors suggest the effect might have been due to the way questions were 
interpreted rather than to the priming of certain information. 'The political questions at the beginning of the interview may have induced respondents to think the survey was about people's lives embedded in the context of societal and political affairs.'

The findings are significant because they reveal the extent to which the standard use of SWB measures discounts the social environment. Surely when we use SWB as a social indicator, a measure of progress, we want to put people's individual lives into a wider context. In contrast, for example, a question I have used in several surveys explicitly includes this social context (as well as broadening the focus beyond the individual): 'Thinking now about the overall quality of life in Australia, taking into account social, economic and environmental conditions and trends, would you say that life in Australia is getting better, worse or staying about the same?' (Eckersley: 2000a, b, 2005). This question is arguably better suited to assessing subjectively national progress. It also produces markedly different results: most people say they are happy and satisfied with their lives; however, when it comes to trends in quality of life, pessimists outnumber optimists. Yet this approach is neglected compared to the growing interest in SWB measures.

The difference in perspectives is highlighted in the headline of a story in The Atlantic in 2012: 'Americans are losing confidence in the nation but still believe in themselves' (Penn: 2012). The article states:

In a wave of pessimism that has been pervasive throughout the last decade (perhaps the longest running in American history), Americans believe their country is heading in the wrong direction, that our values are weathering, that their generation is worse off than their parents' generation, and that their children will be still worse off. Americans believe that political corruption, too much focus on material things, and the influence of money in politics are weakening our values and standing in the world. They believe elected officials reflect and represent mainly the values of the wealthy and think the economic system is unfair to middle- and working-class Americans. And they believe that Wall Street is more like a cancer than an engine for economic growth.

In 2011, Time magazine reported a poll showing that the United States is going through 'one of its longest sustained periods of unhappiness and pessimism ever', adding that it is 'hard to overstate what a fundamental change this represents' (Penn: 2011). Two-thirds of Americans believed the past decade was one of decline, not progress, for the US (68 per cent) and that the greatest threat to the long-term stability of the US came from within, not from outside, the 
country (66 per cent). A half said the past decade was one of the worst in the past 100 years (47 per cent) and that American children today would be worse off than people were when they grew up (52 per cent).

Australia ranks at or near the top of many international comparisons of quality of life and development. Unlike the United States and Europe, it escaped the global financial crisis relatively unscathed: there was no recession, unemployment didn't rise, and national debt is manageable. A refrain in public debate is that Australians have nothing to whine about. Yet, the public mood in Australia is sour; dissatisfaction with government is high. In a 2009 survey, only 24 per cent of people said quality of life in Australia was getting better (ANU Poll: 2009). In another 2009 survey, Australians generally saw themselves today as being richer, but unhappier (or no happier), than they were in the previous few decades (Auspoll: 2009). While 77 per cent said Australians' material standard of living was higher than 20 years ago, 58 per cent felt emotional wellbeing was lower.

The findings stand in stark contrast to people's high levels of self-reported personal happiness and life satisfaction. Why do we persist in telling only half the story?

\section{The mixed blessings of freedom}

The second issue raised in the Diener paper has to do with equating progress with modernisation.

The authors say that the theory of evolutionary modernisation states that people's values and life strategies change as they move from subsistence-level scarcity to high levels of economic and physical security. At low levels of development, sheer survival tends to be the dominant goal and happiness is closely linked with whether one has enough of life's basic necessities. As people attain higher levels of economic and physical security they attach greater importance to having free choice in how to live their lives. They present data on international comparisons showing this: as we move from low-income nations to high, financial satisfaction becomes less important to overall life satisfaction, and free choice becomes more important.

A lot of research shows that personal freedom is a major determinant of progress and human development in cross-country comparisons. In another study, Inglehart and his colleagues linked happiness to the extent to which a society allows free choice; free choice was, in turn, associated with economic development, democratisation, and social liberalisation (Inglehart, Foa, Peterson, Welzel: 2008). Yet studies of the role of freedom in health, both empirical and theoretical, tell a different story (Eckersley: 2002, 2006b, 2009). 
Freedom can be disturbing as well as exciting: while it creates new opportunities for personal experience and growth, it also carries risks of social dislocation and isolation, and a cultural attenuation that makes identity and belonging problematic. This is particularly clear in the sociological work on the centrality of individualisation to late-modern or postmodern life, which is marked by perceived insecurity, uncertainty and risk, and a lack of clear frames of reference.

A new study in Finland - which, with other Scandinavian countries, does well in international comparisons of progress and development - casts fascinating light on this question (Lindfors, Solantas, Rimpela: 2012). It assessed changes in fears for the future of Finnish youth, based on adolescent health and lifestyle surveys carried out in 1983, 1997, and 2007. A total of 17,750 students aged 12-18 were asked an open question: 'When you think about your life and the future in general, what three things do you fear the most?'

Surprisingly, fear of war and terrorism fell over the period, as did fear of environmental disasters. Fear about work and education did not change much, again surprising given the changes in these areas. However, other, more personal fears rose: failure and making wrong choices (from seven per cent to 16 per cent), future family and partnership (seven per cent to 14 per cent), loneliness (five per cent to 20 per cent), accidents (six per cent to 12 per cent), health (16 per cent to 41 per cent), and death (17 per cent to 39 per cent).

The authors conclude that perceptions of risks have become more individualised, thus supporting late-modernist theory. The results highlight the fact that adolescents' images of the future act as a mirror of the times, reflecting the values and ethos of society and its social and cultural norms and their changes over time. 'Cultural and societal changes, including emphasis on individual choice and increased uncertainty, seem to create perceptions of uneasiness and insecurity in young people's transitions to adulthood,' the authors write.

The existential dimension of the analysis can be taken further. In psychology, terror management theory argues that fear of our mortality is a powerful motivation for humans, and we construct personal and cultural means to manage it, to allow us to accept the inevitability of death: worldviews, values, beliefs, rituals. So the Finnish findings, showing increased fear of death, might be further evidence of how Western culture is failing us.

The Diener paper - and the broader SWB literature - does not address this paradox of freedom, although I have noted it in earlier papers. One possibility, which links both the issues I have discussed, is that there is a bias in SWB measurement in favour of individualistic societies, in which people place less emphasis on the social context and more on personal aspects of life. 


\section{Conclusion}

For all their advantages, I believe SWB measures are still missing critical dimensions of human wellbeing: the more intangible, cultural and moral aspects of life that reflect and reveal the depths of the human psyche and the complexities of human affairs. These are the factors that have a major influence on belonging, identity and meaning in life, and so provide the foundation for a sense of intrinsic worth and existential certainty and confidence that are crucial elements of wellbeing.

Replacing or supplementing money with happiness or life satisfaction as a measure won't solve the problem. Although research has revealed the importance of things other than money to wellbeing, there remains a substantial gap in the new progress measures, even those incorporating SWB. Orthodox approaches underestimate the degree to which 'progress' as we measure it is contributing to an existential deficit that is affecting the health and wellbeing of all of us, rich and poor alike. This 'psychosocial dynamics' perspective is largely absent from the political, and even scientific, debate about progress.

However, I admit to being puzzled by these issues. I am impressed by the consistency of SWB findings, the many aspects of life they do seem to reflect. At the same time, SWB researchers seem reluctant to respond to my criticisms, and to venture outside the narrow world of SWB and its correlates to take other, more diverse data into account. This stance can produce what I have called a 'false consensus' that can take hold within scientific disciplines and research fields: an agreement about what is right and important that the wider evidence does not justify.

My work involves transdisciplinary synthesis (Eckersley: 2005, 2010). It ranges well outside social indicators to include, for example, an analysis of the patterns and trends in young people's physical and mental health (Eckersley: 2011). I seek coherence in the overall conceptual picture rather than precision in the empirical detail. The approaches are complementary: they can draw on, inform and balance each other. Yet the value of synthesis is widely overlooked.

My perspective puts me at odds with most empirical approaches, including that of statisticians. I've taken this up with both the Australian Bureau of Statistics and the Australian Institute of Health and Welfare, arguing, for example, that while life expectancy (the most widely used health indicator) may be rigorous, it does not capture the growing importance to health of non-fatal, chronic, physical and mental illness. In avoiding 'sins of commission' (drawing on less rigorous data), statisticians and researchers risk committing 'sins of omission' (not using all the available data). The result can be a failure to get as full and true a picture of life today as they otherwise might. 
I suspect my approach would also put me at odds with Ian Castles, who was a formidable advocate for statistical precision and rigour. However, we should not be surprised that what makes a good life - in all its richness, diversity, complexity and subjectivity - defies ready, or precise, quantitative evaluation, including through the use of GDP or SWB. We may be making progress in measuring progress, but we have further to go than many researchers and statisticians appreciate.

\section{References}

ANU Poll (2009). October 2009 frequencies. Canberra: The Australian National University.

Auspoll (2009). Community attitudes to children and young people. Canberra: Australian Research Alliance for Children and Youth.

Castles I (1997). Measuring wealth and welfare: why HDI \& GPI fail. Symposium: wealth, work, wellbeing. Academy of Social Sciences in Australia, 10 November.

Castles I (1998). Short responses. In R Eckersley (ed) Measuring progress: Is life getting better? Collingwood, VIC: CSIRO Publishing: 351-353.

Diener E, Inglehart R, Tay L (in press). Theory and validity of life satisfaction scales. Social Indicators Research. Doi: 10.1007/s11205.012.0076.y.

Eckersley R, Dear K (2002). Cultural correlates of youth suicide. Social Science and Medicine 55 (11): 1891-1904.

Eckersley R (in press). A psychosocial dynamics model of progress and development. Encyclopedia of Quality of Life and Well-being Research. SpringerReference.com

Eckersley R (2000a). The mixed blessings of material progress: Diminishing returns in the pursuit of happiness. Journal of Happiness Studies 1 (3): 267292.

Eckersley R (2000b). The state and fate of nations: Implications of subjective measures of personal and social quality of life, Social Indicators Research 52: 3-27.

Eckersley R (2005). Well and Good: Morality, meaning and happiness, $2^{\text {nd }}$ edition. Melbourne: Text.

Eckersley R (2006a). Progress, sustainability and human wellbeing: Is a new worldview emerging? International Journal of Innovation and Sustainable Development 1940: 306-317. 
Eckersley R (2006b). Is modern Western culture a health hazard? International Journal of Epidemiology 35: 252-258.

Eckersley R (2009). Population measures of subjective well-being: How useful are they? Social Indicators Research 94 (1): 1-12.

Eckersley R (2010). The hazards of synthesis. Australasian Science, July-August, p 40.

Eckersley, R (2011). A new narrative of young people's health and wellbeing. Journal of Youth Studies 14 (5): 627-638.

Eckersley R (2012). Whatever happened to Western civilization? The cultural crisis, 20 years later. The Futurist 46 (6), Nov-Dec: 16-22.

Inglehart R, Foa R, Peterson C, Welzel C (2008). Development, freedom, and rising happiness: A global perspective (1981-2007). Perspectives on Psychological Science 3 (4): 264-285.

Lindfors P, Solantaus T, Rimpela A (2012). Fears for the future among Finnish adolescents in 1983-2007: From global concerns to ill health and loneliness. Journal of Adolescence. Doi: 10.1016/j.adolescence.2012.02.003.

Penn M (2012). Americans are losing confidence in the nation but still believe in themselves. The Atlantic, 27 June.

Penn MJ (2011). The pessimism index. Time, 30 June: 28-29.

Note: All Eckersley publications are available at: http://www.richardeckersley. com.au. 